\title{
Performance of Soil Metal Arch Structures
}

\author{
Prof. Hany El Naggar \\ Department of Civil and Resource Engineering, Dalhousie University, Canada \\ Hany.elnaggar@dal.ca
}

Corrugated steel plate (CSP) arches are frequently used in North America as short span arch bridges for railway and highway crossings. CSP structures resist the induced loads through their interaction with the surrounding soil medium. Consequently, current design methods for CSP culverts are shifting towards the soil element of the composite soil-metal system. These systems are commonly characterized by their complex soil-structure interaction as the backfill soil of such structures play an integral role in the interaction where its material inelasticity coupled with its complicated stress-dependent stiffness controls the behaviour and require special modelling procedure.

In this paper, rigorous finite element models using PLAXIS 2D were developed to simulate CSP arches in different site conditions. The developed models were verified against a full-scale field study. The study was then extended to include arches with various spans and different cross sections, buried in different site conditions. This study is expected to help better understand the performance of soil-metal structures and to provide useful recommendations on their analysis and design.

Keywords: Soil-metal structures, full-scale field study, stress-dependent stiffness, SSI, finite element analysis. 